\title{
FORECASTING URBAN EXPANSION BASED ON NIGHT LIGHTS
}

\author{
D. Stathakis \\ Dept. of Planning and Regional Development, University of Thessaly, Volos, 38334, Greece - dstath@uth.gr
}

\author{
Commission VIII, WG VIII/8
}

KEY WORDS: Urban expansion, forecasting, DMSP/OLS, night lights, stable lights, urban sprawl, planning

\begin{abstract}
:
Forecasting urban expansion models are a very powerful tool in the hands of urban planners in order to anticipate and mitigate future urbanization pressures. In this paper, a linear regression forecasting urban expansion model is implemented based on the annual composite night lights time series available from National Oceanic and Atmospheric Administration (NOAA). The product known as 'stable lights' is used in particular, after it has been corrected with a standard intercalibration process to reduce artificial year-to-year fluctuations as much as possible. Forecasting is done for ten years after the end of the time series. Because the method is spatially explicit the predicted expansion trends are relatively accurately mapped. Two metrics are used to validate the process. The first one is the year-to-year Sum of Lights $(\mathrm{SoL})$ variation. The second is the year-to-year image correlation coefficient. Overall it is evident that the method is able to provide an insight on future urbanization pressures in order to be taken into account in planning. The trends are quantified in a clear spatial manner.
\end{abstract}

\section{INTRODUCTION}

Urbanization proceeds at a rapid pace in many parts of the globe and significantly affects the environment as well as the quality of life (Grimm et al., 2008; Seto et al. 2012). Therefore there is a need to monitor urbanization and forecast future urbanization pressures in order to reduce their side effects via planning. There are two main types of urban expansion forecasting models depending on the degree of spatial explicitness. The first and less exact one uses aggregated units, such as administrative divisions, to exploit the time series and forecast the result. For example, the percentage of urban extent increase can be forecast per municipality in a city. The second type of models is more exact. Raster data are used as a time series and forecasting is done per pixel. A typical example in this category is the SLEUTH model (Clarke, 2008; Pramanik and Stathakis, 2015) where several urbanization parameters (slopes, evolution of past urban areas, land use etc.) are input and the model predicts the probability of each pixel being urbanized in the future.

The latter type of models has an additional merit. Rather than merely revelling the magnitude of the phenomenon it also reveals the spatial patterns of urbanisation trends (e.g. monocetric vs. poly-centric development, intra-urban peri-urban or exurban growth, road stripe or coastal sprawl etc). Revealing urbanization patterns is fundamental to understand the driving factors of the phenomenon and subsequently be able to better design planning policies (Triantakonstantis and Stathakis, 2015). The fact that the latter type (exact models) is based on the raster structure makes them particularly suitable for use with remote sensing data which are also, by design, structured as rasters. Given the resent plethora of remote sensing datasets this is an exceptionally convenient aspect.

Past urban extent studies have been mainly based on optical data, in specific on LANDSAT and MODIS data, due to the relatively extensive times series they offer (since 1972 and 1999 respectively). The problem in using these two data sources is that extracting urban areas is not a trivial task. Urban areas are spectrally mixed with barren land in many parts of the globe due to the similarity of building materials to natural elements (soil, sand, rocks etc.). Therefore the process is not straightforward, it is laborious and typically needs to be combined with ancillary data that are not always available or cheap (Stathakis and Faraslis 2014; Stathakis et al. 2012). In this framework, it has been recently suggested that it is more efficient to use night time instead of day time optical data.

The Defence Meteorological Satellite Program - Operational Linescan System (DMSP/OLS) data in particular has been used in several urbanization studies. The main advantage stems from the fact that night lights observed from space is a quite straightforward indication of human presence as inhabited areas are clearly outlined (Imhoff et al. 1997a). Night lights have been used to study urbanization at global, continental and national scales (Elvidge et al. 2007, Elvidge et al. 2014; Imhoff et al., 1997A; Imhoff et al., 1997b; Gao et al., 2015; Fan et al., 2014; Ma et al., 2012; Liu et al., 2012; Small and Elvidge. 2013). It has been found that stable lights significantly correlate with population and Gross Domestic Product (GDP) data (Wu et al. 2013; Mellander et al. 2013), both pillars of urbanization.

The main objective and novelty of this paper is the use of DMSP/OLS time series to establish a regression model in order to forecast urban pressures in a spatially explicit manner.

\section{DATA AND STUDY AREA}

\subsection{Study areas}

Two case studies are selected as shown in Figure 1.

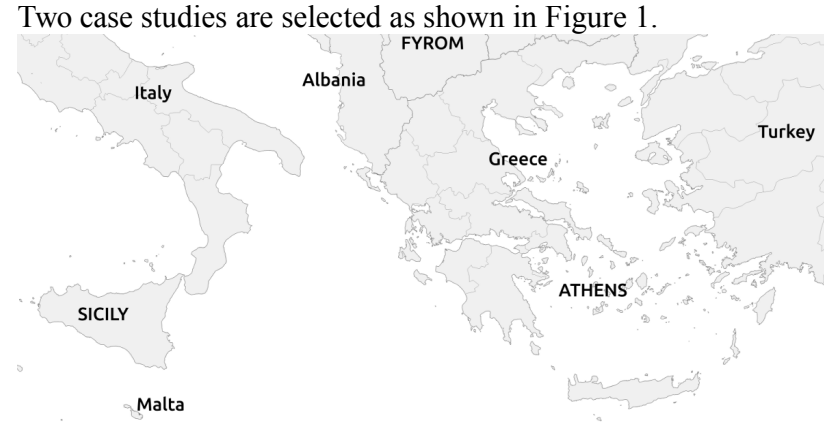

Figure 1. The study areas. Sicily and Athens. 
The first one is Sicily, in the south of Italy, and the second is Athens, the capital of Greece. Sicily is an area where the full range of possible digital number $(\mathrm{DN})$ values is present. Its population is approximately five million people, relatively stable in the past twenty years. Athens is a metropolitan area, of slightly less than four million people. Its urban extent rapidly expanded due to newly built infrastructure (metro, highways, a new airport etc) for 2004 Olympic games.

\subsection{Data}

The OLS sensor records data in $0.5-0.9 \mu \mathrm{m}$ VNIR (Elvidge et al. 1999), approximately corresponding to LANDSATs panchromatic band. Images are captured during the night, typically between 8:30 and 9:30 p.m. local time (Amaral et al. 2005 ). The radiometric resolution is six bits (DN in $[0,63]$ ) (Elvidge et al. 1999). OLS is much more sensitive compared to LANDSAT TM, detecting at least four times lower reflection (Elvidge et al. 1999, Imhoff et al. 1997a).

Currently, the most used form of night lights is the 'stable lights' annual composite product in which daily data are processed and ephemeral lights are removed (Baugh et al. 2010). The spatial resolution of 'stable lights' is approximately $1 \mathrm{~km}$ at the equator. The time series currently includes 23 annual composites (19922013). A subset of them is presented in Figure 2.

\section{METHOD}

\subsection{Intercalibration}

The 'stable lights' product of the Global DMSP-OLS Nighttime Lights Time Series 1992 - 2013 (Ver. 4) has been downloaded from the NOAA website and used in this study. In order to reduce year-to-year fluctuations due to differences in sensor calibration, in acquisition times etc. the standard second order regression intercalibration process has been applied (Elvidge et al., 2009a). Equation 1 is the intercalibration formula.

$$
D N_{c}=a+b \cdot D N_{o}+c \cdot D N_{o}^{2}
$$

where $\quad \mathrm{DN}_{\mathrm{o}}=$ digital number value of stable lights

$\mathrm{DN}_{\mathrm{c}}=$ intercalibrated $\mathrm{DN}$ value

$\mathrm{a}, \mathrm{b}, \mathrm{c}=$ coefficients of the intercalibration function

\begin{tabular}{|c|c|c|c|c|c|c|}
\hline year & F10 & F12 & F14 & F15 & F16 & F18 \\
\hline 1992 & 15.0 & & & & & \\
\hline 1993 & 34.6 & & & & & \\
\hline 1994 & 39.0 & $(12.7)$ & & & & \\
\hline 1995 & & 49.0 & & & & \\
\hline 1996 & & 46.9 & & & & \\
\hline 1997 & & 40.1 & $(32.3)$ & & & \\
\hline 1998 & & 43.1 & $(42.6)$ & & & \\
\hline 1999 & & $(27.8)$ & 41.3 & & & \\
\hline 2000 & & & $(46.3)$ & 50.2 & & \\
\hline 2001 & & & $(42.4)$ & 48.3 & & \\
\hline 2002 & & & $(36.3)$ & 53.8 & & \\
\hline 2003 & & & $(25.8)$ & 48.9 & & \\
\hline 2004 & & & & 55.6 & $(49.3)$ & \\
\hline 2005 & & & & 56.7 & $(50.4)$ & \\
\hline 2006 & & & & 50.8 & $(35.6)$ & \\
\hline 2007 & & & & $(42.9)$ & 50.4 & \\
\hline 2008 & & & & & 45.8 & \\
\hline 2009 & & & & & 34.2 & \\
\hline 2010 & & & & & & 54.5 \\
\hline 2011 & & & & & & 54.1 \\
\hline 2012 & & & & & & 50.3 \\
\hline 2013 & & & & & & 59.2 \\
\hline
\end{tabular}

Table 1. Average cloud-free observations per pixel for each satellite year of stable lights. Discarded data in parenthesis.
The coefficients of the intercalibration function are derived by regression. Each year is compared to a fixed area, termed invariant region, for a specific year, termed base year. In addition, the presumed noise has been removed in all images in the time series by applying the threshold in Equation (2)

$$
D N^{\prime}=\left\{\begin{array}{c}
0, \text { if } D N \leq 6 \\
D N, \text { otherwise, }
\end{array}\right.
$$

where $\mathrm{DN}^{\prime}$ is the new value and $\mathrm{DN}$ is the original value.

\subsection{Selection of intercalibrated satellite year.}

In several instances, there are two satellites operating concurrently (Hsu et al, 2015). Therefore, two stable light products per year are produced, as shown in Table 1. A reasonable approach to select one of the two annual composites is to keep the one with the highest averaged number of cloudfree observations of each pixel that is provided as metadata by NOAA for each annual stable lights product (Li et al. 2013). This information is also shown in Table 1.

\subsection{Linear regression forecasting}

A linear regression model is fitted to the raster time series using Equation 3. The linear model is fitted per pixel (not a single one for the total raster).

$y=a+b x$

where $a$ is the line intercept, $b$ is its slope, $x$ is the raster of the previous year and $y$ is the raster of the next year (forecast).

The output is also corrected to the original range by applying the threshold

$$
D N^{\prime}=\left\{\begin{array}{c}
63, \text { if } D N>63 \\
D N, \text { otherwise, }
\end{array}\right.
$$

where $\mathrm{DN}^{\prime}$ is the new value and $\mathrm{DN}$ is the original value.

\subsection{Validation metrics}

As a means to observe and validate the forecasting quality of two metrics are used. The first one is the evolution of the Sum of Lights (SoL). SoL is the sum of all DN values in an area ( $\mathrm{Li}$ et al. 2013). SoL is calculated per region, by a possess frequently termed zonal statistics, as shown in Equation (2).

$S o L=\sum_{i} D N_{i}$

where $\mathrm{DN}_{\mathrm{i}}$ is the digital number value.

The second metric is the year-to-year Pearson correlation coefficient between the current and next date rasters in pairs.

\subsection{Limitations}

Clearly the linear regression model is a simplification of the urban expansion trends. Other, more complex models can be used. The linear model is used as a first step to understand the capacity of the method and has the advantage of straightforward interpretation of its coefficients. Also, any regression model fails to take into account contextual information (neighbouring relationships) and predict urbanization is new locations (where lights do not currently exhibit an increasing trend). In addition, it is assumed here that night lights are a perfect indicator of urban expansion. However, this is not true for several reasons ranging from energy saving policies to development stages and types (Stathakis et al, 2015). Nevertheless, it is a fact that night lights strongly correlate with urban expansion. This is enough to make a valid time series and forecast. 

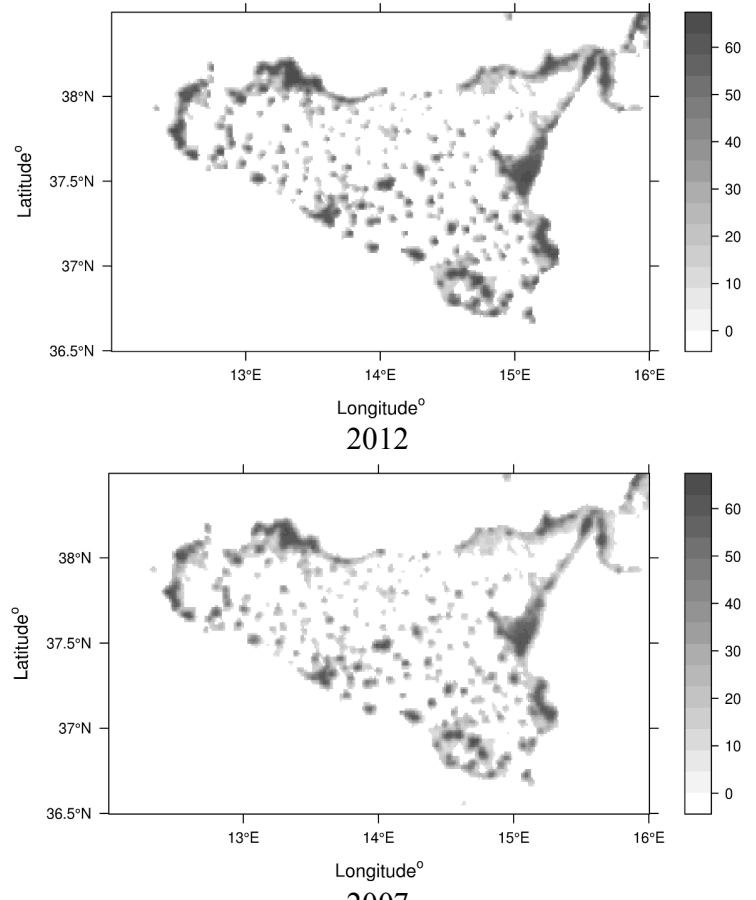

2007

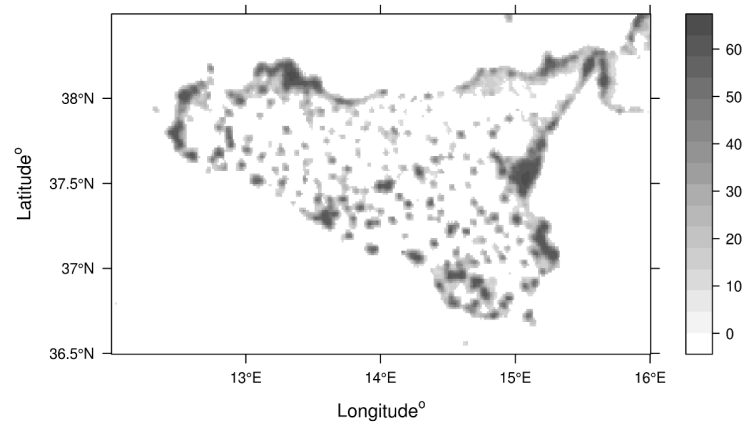

2002

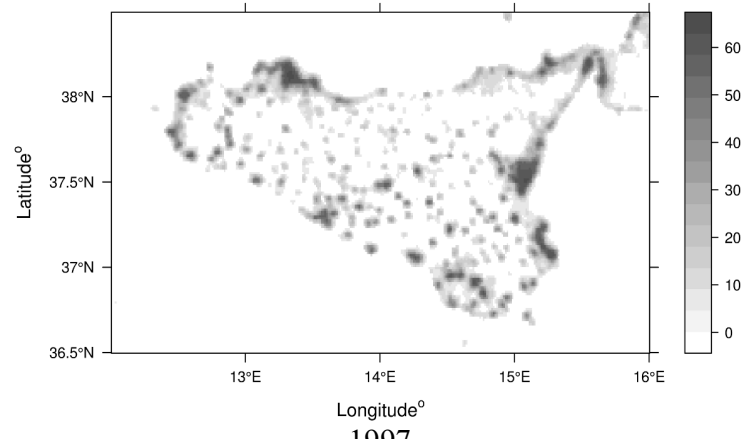

1997

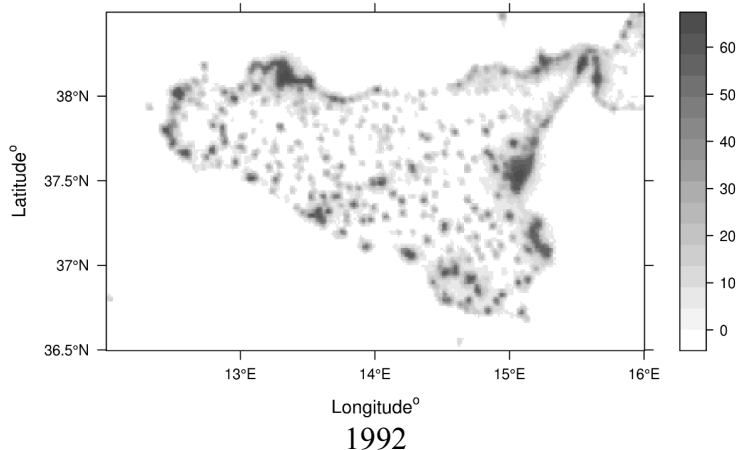

Figure 2. Time series of night lights for Sicily (left) and Athens (right).

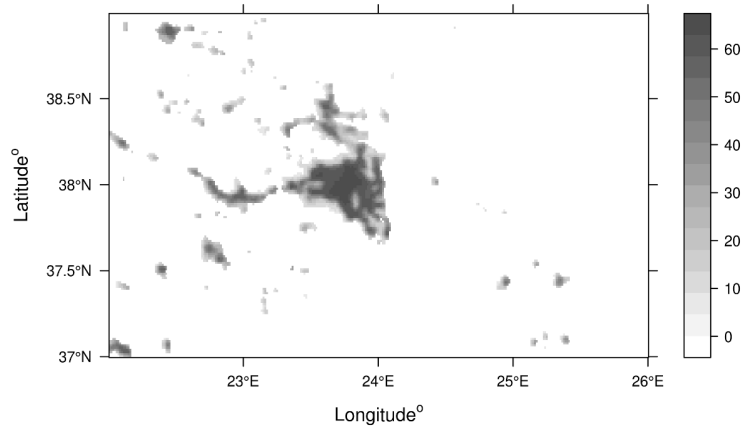

2012

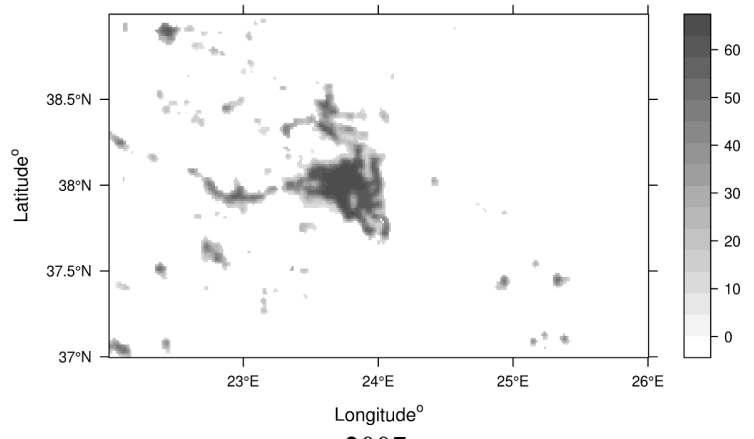

2007
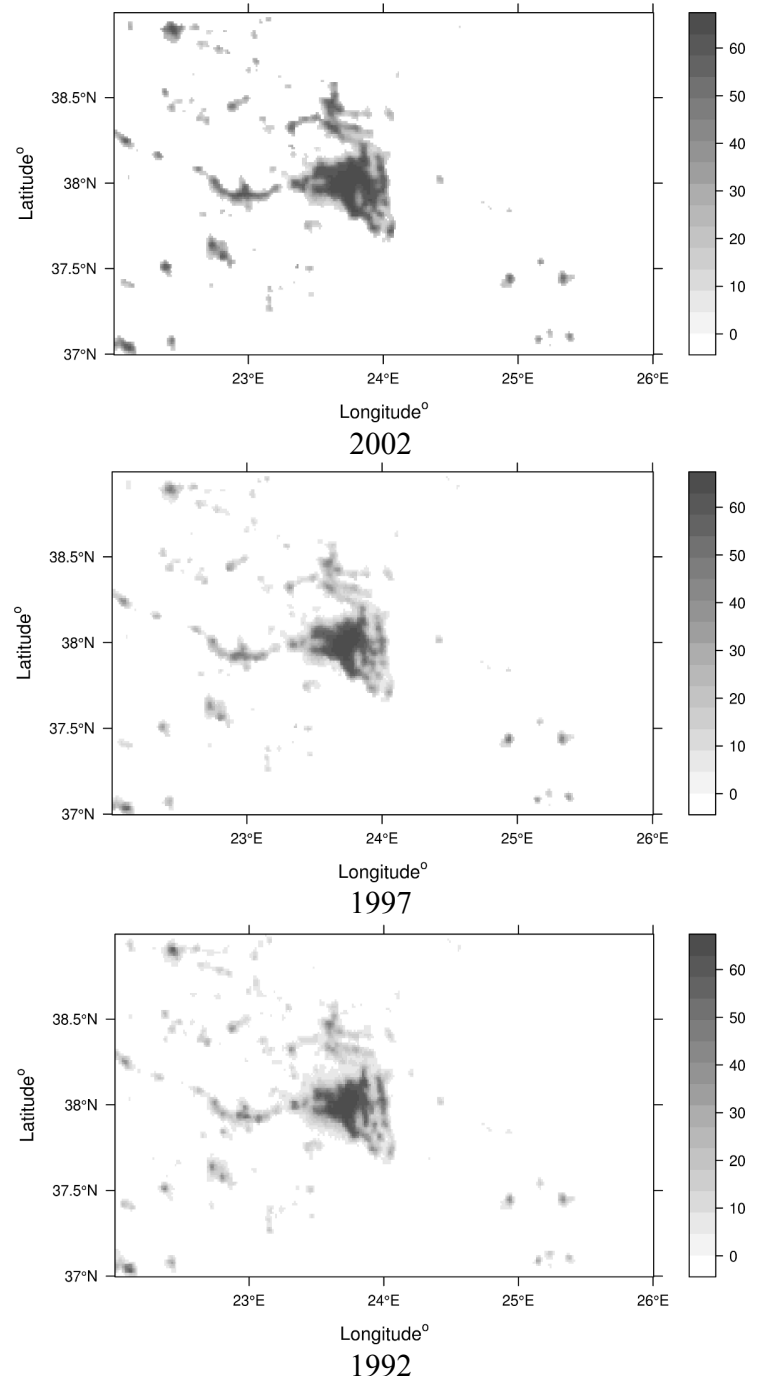

Data every five years are shown (i.e. 5 out of the 23 in total annual composites available). 


\section{RESULTS}

The expected change in DN values in five years time is shown in Figure 3(a). Expected change is calculated as

$$
D N_{d}=D N_{e}-D N_{c}
$$

$$
\text { where } \quad \begin{aligned}
& \mathrm{DN}_{\mathrm{d}}=\text { difference } \\
& \mathrm{DN}_{\mathrm{e}}=\text { estimated } \mathrm{DN} \text { values in } 5 \text { years } \\
& \mathrm{DN}_{\mathrm{c}}=\text { current }(2012) \mathrm{DN} \text { values }
\end{aligned}
$$

The predicted maps for the next five years are shown in Figure 3(b). The year-to-year SoL and image correlation coefficients are shown in Figure 3(c) and Figure 3(d) respectively.

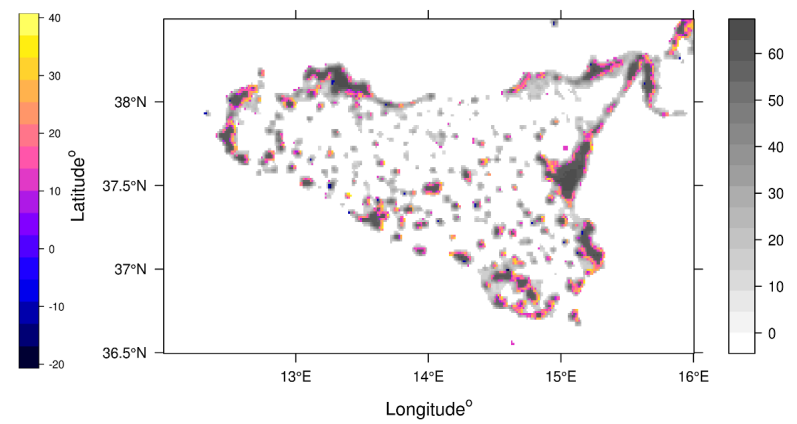

(a) forecast change in the next 5 five years $(2013-2018)$

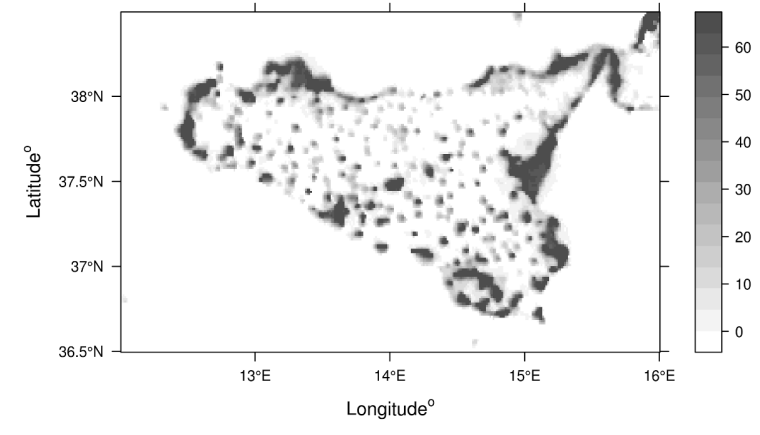

(b) forecast $2018(+5$ years $)$

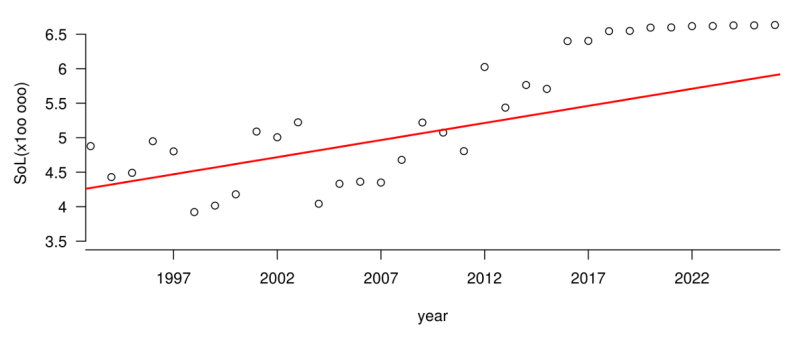

(c) SoL year-to-year variation

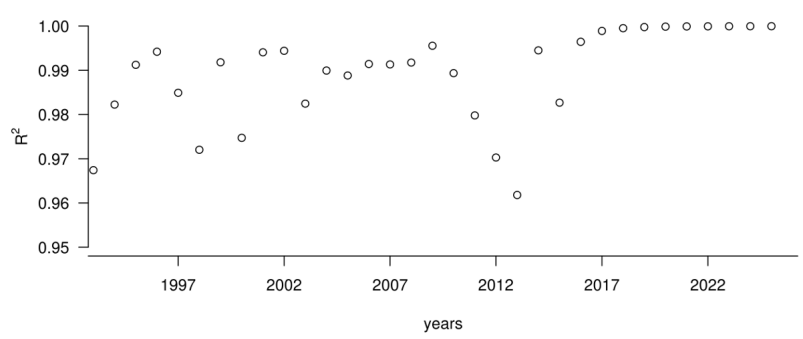

(d) $\mathrm{R}^{2}$ year-to-year variation

Figure 3. Forecast results for Sicily (left) and Athens (right)
The rightmost part of the diagrams in these two last figures is relatively stable after 2013 because it refers to the forecast data.

For Sicily, future urban expansion pressures are primarily focused on the coastal and peri-urban areas. For Athens there is a clear evidence of urban pressures along the new highway as well as towards the east coastline as a result of the new infrastructure built for 2004 Olympic games (airport and highways).
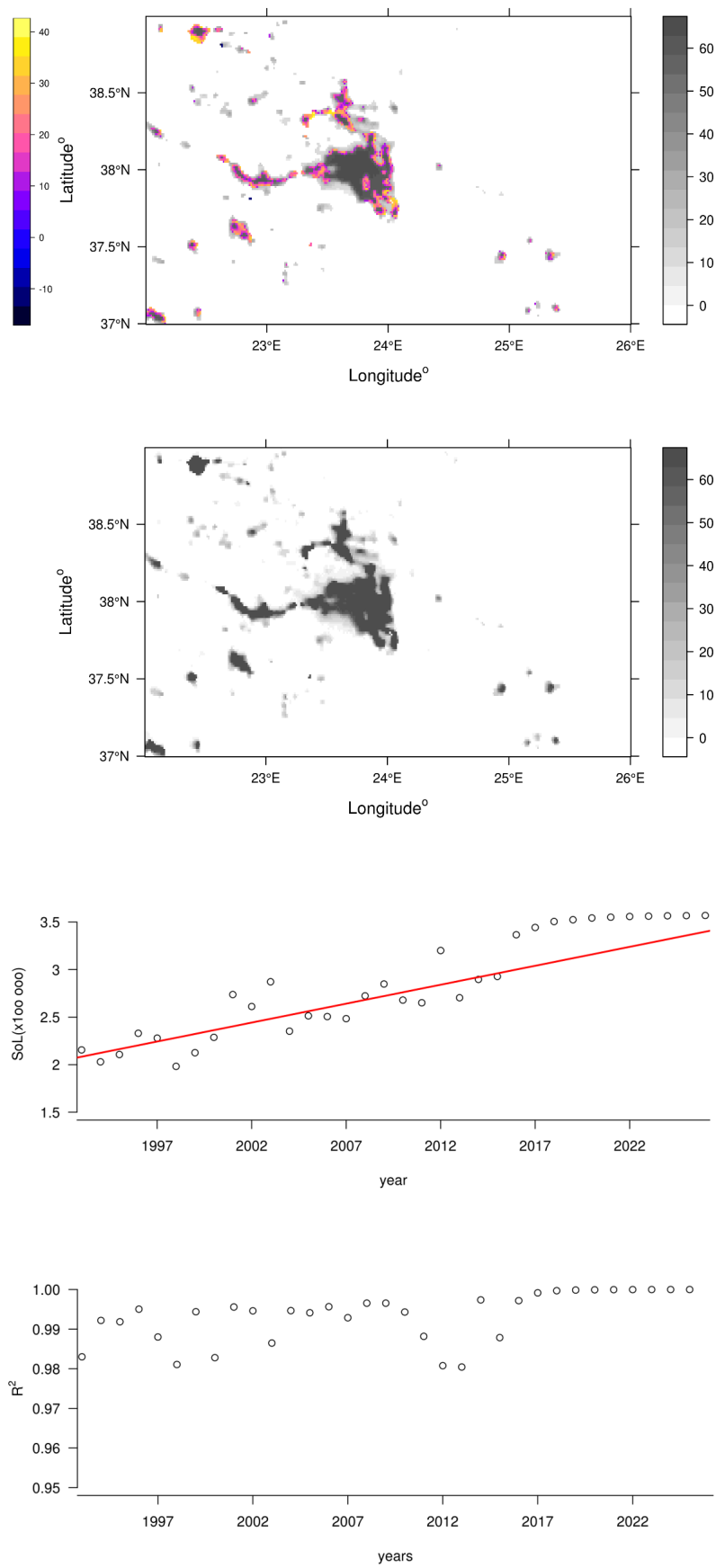


\section{CONCLUSION}

A linear regression model has been deployed to quantify future urban extent trends based on night lights time series. The practical value of the method consists mainly on the relatively easiness with which the time series is constructed, compared to day time optical data. The method can be applied near globally to obtain a quick estimate of which areas will be under urbanization pressures in the future provided that the assumptions proposed hold (i.e. that night time lights strongly correlate with urban expansion and past driving factors remain in the future).

Because the prediction is based on the regression line the effect of the year-to-year variation, that remains in the time series even after intercalibration is applied, is further generalized and reduced.

The method can be improved in the future by fitting other models to project the data, including non-linear regression functions and neural networks. The use of non-linear functions will also allow to obtain more reliable quantitative results and make specific estimates of urbanization increase per region in time.

\section{ACKNOWLEDGEMENTS}

Version 4 DMSP-OLS Nighttime Lights Time Series Image and data processing by NOAA's National Geophysical Data Center. DMSP data collected by US Air Force Weather Agency.

\section{REFERENCES}

Amaral S., Camara G., Monteiro A., Quintanilha J., and C. Elvidge, 2005, Estimating population and energy consumption in Brazilian Amazonia using DMSP night-time satellite data, Computers, Environment and Urban Systems, 29, pp. 179-195.

Baugh K., Elvidge C., Ghosh T. and D. Ziskin, 2010, Development of a 2009 stable lights product using DMSP-OLS data. Proc. Asia-Pacific Adv. Net. 30, pp. 114-130.

Clarke, K.C., 2008. A Decade of Cellular Urban Modeling with SLEUTH: Unresolved Issues and Problems, Ch. 3 in Planning Support Systems for Cities and Regions, Ed. Brail, R. K., Lincoln Institute of Land Policy, Cambridge, MA, pp. 47-60.

Elvidge C., Tuttle B., Sutton P., Baugh K., Howard A. , Milesi C., Bhaduri B. and N. Ramakrishna, 2007, Global Distribution and Density of Constructed Impervious Surfaces, Sensors, 7, pp. 1962-1979.

Elvidge C, Baugh K., Dietz J., Bland T., Sutton P., and H. Kroehl, 1999, Radiance calibration of DMSP-OLS low-light imaging data of human settlements, Remote Sensing of Environment, 68, pp. 77-88.

Elvidge C, Hsu F-C, Baugh K., T. and Gosh, 2014, National trends in satellite-observed lighting 1992-2012, in Global Urban Monitoring and Assessment through earth observation, Edited by Q. Weng, CRC Press, pp. $97-120$.

Elvidge C., Ziskin D., Baugh K., Tuttle T., Ghosh T., Pack W., Erwin H., and M. Zhizhin, 2009, A fifteen year record of global natural gas flaring derived from satellite data., Energies 2(3), pp. 595-622.

Fan J., Ma T., Zhou C., Zhou Y. and T. Xu, 2014, Comparative Estimation of Urban Development in China's Cities Using Socioeconomic and DMSP/OLS Night Light Data, Remote Sensing, 6(8), pp. 7840-7856.
Hsu F, Baugh K, Ghosh T., Zhizhin M., and Elvidge C., 2015, DMSP-OLS Radiance Calibrated Nighttime Lights Time Series with Intercalibration, Remote Sensing 7, pp. 1855-1876.

Imhoff M., Lawrence W., Elvidge C. Paul T., Levine E., Privalsky M., and V. Brown, 1997a, Using nightitme DMSP/OLS images of city lights to estimate the impact of urban land use on soil resources in the united states, Remote Sensing of Environment, 59, pp. 105-117.

Imhoff M., Lawrence W., Stutzer D., and C. Elvidge, 1997b, A technique for using composite DMSP/OLS "city lights" satellite data to map urban area, Remote Sensing of Environment, 61, pp. 361-370.

Gao B., Huang Q., He C. and Ma Q., 2015, Dynamics of Urbanization Levels in China from 1992 to 2012: Perspective from DMSP/OLS Nighttime Light Data, Remote Sensing, 7(2), pp. 1721-1735.

Grimm, N., et al., 2008, Global change and the ecology of cities, Science, 319, pp. 756-760.

Liu Z., He C., Zhang Q., Huang Q., and Y. Yang, 2012, Extracting the dynamics of urban expansion in China using DMSP-OLS nighttime light data from 1992 to 2008, Landscape and Urban Planning, 106, pp. 62- 72.

Li X., Chen X., Zhao Y., Xu J., Chem F., Li H., 2013, Automatic intercalibration of night-time light imagery using robust regression, Remote Sensing Letters, 4(1), pp. 45-54 .

Ma T. Zhou C., Pei T., Haynie S., and J. Fan, 2012, Quantitative estimation of urbanization dynamics using time series of DMSP/OLS nighttime light data: A comparative case study from China's cities, Remote Sensing of Environment, 124, pp. $99-107$.

Mellander C.,Stolarick K., Matheson Z. and J. Lobo, 2013, Night-Time Light Data: A Good Proxy Measure for Economic Activity?, The Royal Institute of technology Centre of Excellence for Science and Innovation Studies (CESIS), June, Electronic Working Paper Series Paper No. 315, Sweden, 13 Aug., pp. 32 https://static.sys.kth.se/itm/wp/cesis/cesiswp315.pdf

Pramanik M. and D. Stathakis, 2015. Forecasting urban sprawl in Dhaka city of Bangladesh, Environment and Planning B: Planning and Design, August 3, doi: 10.1177/0265813515595406.

Seto K., Gueneralp B., and L. Hutyra, 2012, Global forecasts of urban expansion to 2030 and direct impacts on biodiversity and carbon pools, Proceedings of the National Academy of Sciences of the United States of America 109.40, pp. 16083-16088. DOI: 10.1073/pnas.1211658109/-/DCSupplemental

Small C., Elvidge C., 2013, Night on Earth Mapping decadal changes of anthropogenic night light in Asia, International Journal of Applied Earth Observation and Geoinformation, 22, pp. $40-5$.

Stathakis, D. and I Faraslis, 2014, Monitoring urban sprawl using simulated PROBA-V data, International Journal of Remote Sensing, 35 (7), pp. 2731-2743.

Stathakis, D., Perakis, K., Savin, I., 2012, Efficient segmentation of urban areas by the VIBI, International Journal of Remote Sensing, 33 (20), pp. 6361-6377. 
Stathakis D., Tselios V., and I. Faraslis, 2015, Urbanization in European regions based on night lights, Remote Sensing Applications: Society and Environment, 2, pp. 26-34.

Triantakonstantis D and D. Stathakis, 2015, Urban Growth Prediction in Athens - Greece, Using Artificial Neural Networks, World Academy of Science, Engineering and Technology International Journal of Civil, Structural, Construction and Architectural Engineering, 9(3), p. 5.

Wu J., Wang Z., Li W., Peng J., 2013, Exploring factors affecting the relationship between light consumption and GDP based on DMSP/OLS nighttime satellite imagery, Remote Sensing of Environment, 134, pp. 111-119.

Revised March 2016 